\title{
Mineralogia e química dos sedimentos de fundo do médio e baixo Madeira e de seus principais tributários - Amazonas - Brasil
}

\begin{abstract}
Maria Mireide Andrade QUEIROZ ${ }^{1}$, Adriana Maria Coimbra HORBE², Candido Augusto Veloso MOURA ${ }^{3}$
RESUMO

O objetivo deste trabalho foi investigar a variação composicional e mineralógica dos sedimentos de fundo transportados pelos grandes rios da Amazônia, com nascentes nos Andes provenientes de rochas cratônicas. O estudo foi realizado com base em análises granulométricas, mineralógicas e químicas, incluindo isótopos de $\mathrm{Pb}$, no rio Madeira e seus tributários. O conjunto de dados mostra que os sedimentos de fundo do rio Madeira são granulométrica, mineralógica e quimicamente distintos de seus principais tributários. Os sedimentos do rio Madeira são mais arenosos; têm maior quantidade de quartzo; menor conteúdo de $\mathrm{Al}_{2} \mathrm{O}_{3}, \mathrm{Fe}_{2} \mathrm{O}_{3}, \mathrm{~K} 2 \mathrm{O}, \mathrm{MgO}, \mathrm{Na}_{2} \mathrm{O}, \mathrm{PF}, \mathrm{TiO}_{2}, \mathrm{P}_{2} \mathrm{O}_{5}, \mathrm{MnO}$ e elementos-traço; e a maturidade aumenta de montante para jusante. Dentre os sedimentos dos tributários, os rios Machado e secundariamente o rio Marmelos são os que mais se aproximam da composiçáo dos sedimentos do rio Madeira, enquanto que o Jamari com sedimentos com maior proporção de $\mathrm{TiO}_{2}, \mathrm{Zr}$, $\mathrm{Y}$, $\mathrm{Nb}, \mathrm{Ga}, \mathrm{Hf}, \mathrm{U}$, Ta e ETR, é o mais distinto. Apesar do ambiente de intenso intemperismo e erosão, em condiçóes tropicais úmidas, a que estão submetidas as rochas drenadas pela bacia do rio Madeira, os valores das razóes $\mathrm{Th} / \mathrm{Co}, \mathrm{Th} / \mathrm{Pb}, \mathrm{Th} / \mathrm{Yb}, \mathrm{Al} /$ $\mathrm{Pb}, \mathrm{Zr} / \mathrm{Co}$ e a composição isotópica de $\mathrm{Pb}$ indicam fontes distintas para os sedimentos de fundo estudados. Os sedimentos do rio Madeira são provenientes, principalmente, de rochas máficas, enquanto que os sedimentos de seus tributários têm como fonte essencialmente rochas félsicas.
\end{abstract}

PALAVRAS-CHAVE: Geoquímica, isótopos de Pb, águas brancas e pretas

\section{Mineralogy and chemistry of bottom sediments of the middle and lower Madeira River and its main tributaries - Amazonas - Brazil}

\begin{abstract}
This study reports the granulometric, mineralogic and chemical analyses, including $\mathrm{Pb}$ isotope, carried out on the bottom sediments of the Madeira River, whose headwaters are in the Andes Mountain, and its tributaries that come from the cratonic region, in order to investigate the compositional variation of the sediments transported by the major rivers of the Amazon. The analytical data show that the bottom sediments of the Madeira River have higher amounts of sand and quartz, and lower contents of $\mathrm{Al}_{2} \mathrm{O}_{3}, \mathrm{Fe}_{2} \mathrm{O}_{3}, \mathrm{~K} 2 \mathrm{O}, \mathrm{MgO}, \mathrm{Na}_{2} \mathrm{O}, \mathrm{PF}, \mathrm{TiO}_{2}, \mathrm{P}_{2} \mathrm{O}_{5}, \mathrm{MnO}$ and trace elements, and the maturity increases toward downstream. Among the tributaries, the bottom sediments from Machado and, secondarily, Marmelos rivers are those that more closely match the composition of the sediments of Madeira River. The sediments of Jamari River, with higher proportion of $\mathrm{TiO}_{2}, \mathrm{Zr}, \mathrm{Y}, \mathrm{Nb}, \mathrm{Ga}, \mathrm{Hf}, \mathrm{U}, \mathrm{Ta}$ and REE, are quite distinct. In spite of the intense weathering and erosion, in humid tropical conditions, that the rocks drained by the Madeira river basin have been submitted, the Th/Co, Th/ $\mathrm{Pb}, \mathrm{Th} / \mathrm{Yb}, \mathrm{Al} / \mathrm{Pb}, \mathrm{Zr} / \mathrm{Co}$ ratios and $\mathrm{Pb}$ isotope data indicate that different sources contributed to the bottom sediments. It is suggested that mafic rocks are the main source of the sediments of the Madeira River, while felsic rocks are the source of the tributaries.
\end{abstract}

KEYWORDS: Geochemistry, isotope of $\mathrm{Pb}$, white and black water.

\footnotetext{
1 Universidade Federal do Pará, Instituto de Geociências. Rua Augusto Correia, 1 - Guamá. CEP: 66075-110 Belém, PA. e-mail: mireidequeiroz@yahoo.com.br

2 Universidade Federal do Amazonas, Departamento de Geociências. Curso de Pós-Graduação. Av. General Rodrigo Otávio Jordão Ramos, 3000 - Japiim. CEP: $69077-000$ Manaus, AM. e-mail: ahorbe@ufam.edu.br

${ }^{3}$ Universidade Federal do Pará, Instituto de Geociências. Rua Augusto Correia, 1 - Guamá. CEP: 66075-110 Belém, PA. e-mail: candido@ufpa.br
} 


\section{INTRODUÇÃO}

Os rios são as principais vias por onde os produtos de erosão, provenientes do continente, alcançam os oceanos. As composiçóes destes produtos, química e isotópica, podem ser influenciadas por vários fatores, que incluem: 1) ambiente geológico (composição, diagênese, metamorfismo e taxa de intemperismo das rochas) da bacia de drenagem; 2) clima; 3) classificação hidráulica; 4) aportes eólicos e glaciais e 5) atividades antropogênicas (Goldstein e Jacobsen 1988; Fralick e Kronberg 1997). A interação destes fatores, os processos físicos e químicos envolvidos e até como variou a composição da crosta continental superior ao longo do tempo podem ser medidos estudando-se as fraçóes particuladas e dissolvidas dos grandes rios do mundo (Negrel et al. 1993, Millot et al. 2004). Contudo, a composição química do material transportado pela água ao longo dos rios pode ser modificada devido ao aporte de afluentes e a variação do substrato geológico, o que dificulta sua correlação com a rocha fonte (Borges et al. 2008). Para isso, utilizam-se como parâmetros: a mineralogia e a química dos minerais resistatos, e a química dos sedimentos com ênfase nos elementos imóveis como Al, Ti, Th, Sc, Co, $\mathrm{Zr}$ e ETR, que são pouco fracionados durante os processos de intemperismo, e concentram-se no material em suspensão e no sedimento de fundo em detrimento da fração dissolvida dos rios (Taylor e McLennan 1985).

O rio Madeira tem nascente na Bolívia a partir da confluência dos rios Guaporé, Mamoré, Beni e Madre de Dios e, ao longo do seu curso, recebe inúmeros afluentes (Abunã, Jaci-Paraná, Candeias do Jamari, Machado, Marmelos, Aripuanã, Canumã, Madeirinha e Acará). Este conjunto de rios, que forma a bacia do Madeira, drena rochas da cordilheira dos Andes, do Cráton Brasileiro e da bacia do Amazonas e tem vastas planícies aluviais formadas a partir da deposição de sedimentos carreados por essas drenagens (Figura 1).

Poucos estudos foram feitos no rio Madeira. Martinelli et al. (1993), Guyot et al. (2007) e Lyons e Bird (1995) identificaram, nos sedimentos de fundo e em suspensão, illita, caulinita, clorita e esmectita. Há um pouco mais de detalhes sobre a química da água nas suas cabeceiras (Elbaz-Poulichet et al. 1999; Dosseto et al. 2006b) e próximo à confluência com o rio Amazonas (Gibbs, 1967; Martinelli et al. 1993; Gaillardet et al. 1997; Benedetti et al. 2003; Mortatti e Probst, 2003; Seyler e Boaventura, 2003; Seyler et al. 2003; Tardy et al. 2005; Dosseto et al. 2006).

Com o objetivo de avaliar como variam e quais as influências a que estấo submetidos os sedimentos de fundo transportados pelos grandes rios da Amazônia, como o Madeira, cujas nascentes estáo nos Andes, enquanto seus afluentes provêm de rochas cratônicas, foram estudadas suas características granulométricas, mineralógicas e químicas. Foi selecionado o trecho do rio que se estende da cidade de Porto
Velho até a confluência do rio Madeira com o Amazonas, cobrindo $1.050 \mathrm{~km}$ de extensão, o que representa $75 \%$ do percurso total do rio (Figura 1).

\section{CONTEXTO FISIOGRÁFICO E GEOLÓGICO}

A regiáo drenada pelo rio Madeira caracteriza-se pelo clima quente e úmido com estaçáo seca pouco pronunciada, do tipo "Am" na classificaçáo de Koppen (1948). A temperatura anual média varia entre 25 e $27^{\circ} \mathrm{C}$. A umidade relativa do ar é de aproximadamente $85 \%$ e a precipitação de até 2200 $\mathrm{mm} \mathrm{ano}^{-1}$. O período mais chuvoso na região é de janeiro a março, e a época mais seca de junho a agosto. As menores temperaturas verificam-se de junho a julho, com mínimas absolutas de $10{ }^{\circ} \mathrm{C}$ a $16^{\circ} \mathrm{C}$ (CPRM 2001). Segundo Terezo et al. (1975), a floresta domina grande parte da regiáo e o cerrado ocupa apenas ilhas no seu interior, próximo ao limite entre Rondônia e Mato Grosso.

$\mathrm{O}$ rio Madeira drena três unidades morfo-estruturais principais: a cordilheira dos Andes (15\%), o escudo Brasileiro (41\% da bacia) e a planície Amazônica (44\%), com litologia e geomorfologia distintas. A porção estudada da bacia do Madeira, entre Porto Velho e a foz com o Amazonas, está inserida nas duas últimas unidades. O escudo Brasileiro tem geomorfologia baixa, é constituído de platôs e colinas formadas por rochas de idades arqueanas, pré-cambrianas e paleozoicas. A porção da bacia do rio Madeira estudada inclui rochas ígneas e metamórficas do Grupo Colider (riolitos, andesitos e brechas), Suite Intrusiva São Romão (granitos, metagranitos e gnaisses calcialcalinos), Suite Intrusiva Serra da Providência (granito, charnockito, mangerito e rochas máficas), Complexo Jamari (ortognaisse tonalítico, quartzo-diorito, gnaisse calcissilicático e micaxisto) do paleoproterozoico e as sedimentares do Grupo Alto Tapajós (arenitos, siltitos e calcários) (CPRM 2006). Estas rochas compóem as cabeceiras e o médio curso dos afluentes da margem direita do rio Madeira. A planície Amazônica é genericamente subdividida em terras altas e várzeas constituídas pelas rochas sedimentares das formaçóes Alter do Chão (arenitos e conglomerados), Içá (arenitos, argilitos com linhitos e turfa) e depósitos quaternários (silte, areia e seixos) (Figura 1).

\section{MATERIAL E MÉTODOS}

Foram coletadas, em julho de 2007, treze amostras de sedimentos de fundo (Figura 1 e Tabela 1) com o auxílio de uma draga. As amostras, contendo aproximadamente 1 quilograma, foram secas à temperatura ambiente $\left(24^{\circ} \mathrm{C}\right)$, parte do material foi pulverizado para as análises mineralógicas e químicas, enquanto que o restante foi reservado para as análises granulométricas.

Para a análise granulométrica, foram utilizadas $100 \mathrm{~g}$ de sedimento e peneiras de malhas $0,50 \mathrm{~mm} ; 0,25 \mathrm{~mm} ; 0,125$ 


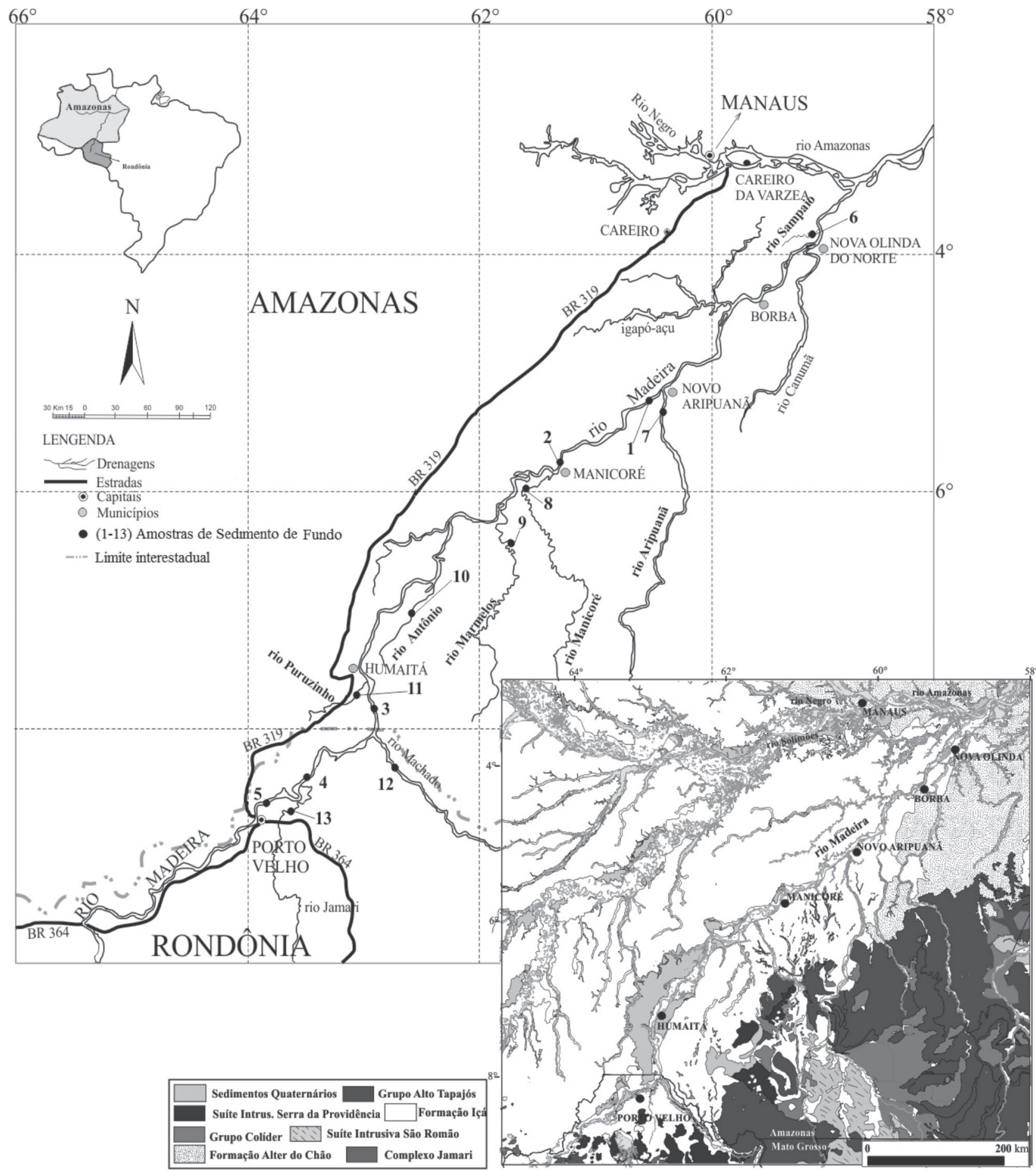

Figura 1 - Mapa geológico e localização das amostras da região estudada.

$\mathrm{mm}$ e $<0,062 \mathrm{~mm}$ em que obteve-se, respectivamente, as fraçóes areia grossa, média, fina e silte + argila. Estas análises foram realizadas no Laboratório de Geoquímica do Departamento de Geociências da Universidade Federal do Amazonas.
As determinações mineralógicas foram feitas por lupa binocular e difração de raios-x no laboratório de Difração de Raios-x do Departamento de Geociências da Universidade Federal do Amazonas. Foi utilizado difratômetro Shimadzu, modelo XRD-6000, equipado com ânodo de cobre $\left(\mathrm{Cuk} \alpha_{1}=\right.$ 
Tabela 1 - Pontos de coletas, coordenadas geográficas e granulometria dos sedimentos de fundo estudados.

\begin{tabular}{|c|c|c|c|c|c|c|c|c|}
\hline \multirow{2}{*}{ Pontos } & \multirow{2}{*}{ Local } & \multicolumn{2}{|c|}{ Coordenadas Geográficas } & \multicolumn{4}{|c|}{ Areia \% } & \multirow{2}{*}{$\begin{array}{c}\text { Silte + argila } \\
\%\end{array}$} \\
\hline & & Latitude & Longitude & grossa & média & fina & muito fina & \\
\hline 1 & rio Madeira & $05^{\circ} 50^{\prime} 58,5^{\prime \prime}$ & $61^{\circ} 36^{\prime} 20,5^{\prime \prime}$ & $<1$ & 24 & 73 & 1 & 2 \\
\hline 2 & rio Madeira & $05^{\circ} 48^{\prime} 19,0^{\prime \prime}$ & $61^{\circ} 22^{\prime} 30,3^{\prime \prime}$ & 7 & 80 & 12 & $<1$ & 1 \\
\hline 3 & rio Madeira & $07^{\circ} 45^{\prime} 36,0^{\prime \prime}$ & $62^{\circ} 56^{\prime} 00,9^{\prime \prime}$ & $<1$ & 59 & 39 & $<1$ & 1 \\
\hline 4 & rio Madeira & $08^{\circ} 15^{\prime} 07,2^{\prime \prime}$ & $63^{\circ} 22^{\prime} 14,5^{\prime \prime}$ & 20 & 35 & 30 & 8 & 7 \\
\hline 5 & rio Madeira & $08^{\circ} 35^{\prime} 44,1^{\prime \prime}$ & $63^{\circ} 47^{\prime} 18,6^{\prime \prime}$ & 1 & 28 & 49 & 19 & 3 \\
\hline 6 & rio Sampaio & $04^{\circ} 05^{\prime} 09,9^{\prime \prime}$ & $59^{\circ} 25^{\prime} 12,0^{\prime \prime}$ & $<1$ & $<1$ & $<1$ & $<1$ & 99 \\
\hline 7 & rio Aripuanã & $05^{\circ} 20^{\prime} 06,0^{\prime \prime}$ & $60^{\circ} 25^{\prime} 25,3^{\prime \prime}$ & 31 & 60 & $<1$ & $<1$ & 8 \\
\hline 8 & rio Manicoré & $06^{\circ} 02^{\prime} 52,4^{\prime \prime}$ & $61^{\circ} 34^{\prime} 39,0^{\prime \prime}$ & 26 & 66 & $<1$ & $<1$ & 7 \\
\hline 9 & rio Marmelos & $06^{\circ} 24^{\prime} 56,1^{\prime \prime}$ & $61^{\circ} 46^{\prime} 33,6^{\prime \prime}$ & $<1$ & 3 & 9 & 13 & 74 \\
\hline 10 & rio Antônio & $06^{\circ} 24^{\prime} 01,1^{\prime \prime}$ & $62^{\circ} 01^{\prime} 24,9^{\prime \prime}$ & $<1$ & $<1$ & $<1$ & $<1$ & 99 \\
\hline 11 & rio Puruzinho & $06^{\circ} 19^{\prime} 17,7^{\prime \prime}$ & $62^{\circ} 21^{\prime} 52,5^{\prime \prime}$ & $<1$ & $<1$ & $<1$ & 4 & 95 \\
\hline 12 & rio Machado & $08^{\circ} 27^{\prime} 48,9^{\prime \prime}$ & $62^{\circ} 33^{\prime} 09,0^{\prime \prime}$ & 27 & 56 & 13 & $<1$ & 3 \\
\hline 13 & rio Jamari & $08^{\circ} 16^{\prime} 58,4^{\prime \prime}$ & $62^{\circ} 59^{\prime} 38,4^{\prime \prime}$ & $<1$ & $<1$ & $<1$ & 4 & 95 \\
\hline
\end{tabular}

As amostras do rio Madeira estão de jusante para montante (Figura 1).

1,5405 A). As condiçôes instrumentais aplicadas nas análises das amostras foram: voltagem: 40,0 (Kv), amperagem: 30 $(\mathrm{mA})$, fendas usadas: $1,0-1,0-0,15$, scan range: $3^{\circ}$ a $60^{\circ}\left({ }^{\circ} 2 \theta\right)$, passo: $0,2^{\circ} 2 \theta$, velocidade: $2^{\circ} 2 \theta / \mathrm{mim}$.

$O$ percentual correspondente a cada mineral encontrado foi obtido conjugando o cálculo estequiométrico de cada mineral, e as análises químicas dos óxidos maiores das amostras (Tabela 2) (Martinelli et al. 1993). Todos os minerais foram detectados por difratometria de raios-x, exceto hematita e goethita encontradas apenas em oólitos identificados por lupa binocular. O método para esse cálculo está detalhado na Tabela 2 e constou dos seguintes passos: 1) foi considerado que todo o $\mathrm{MgO}$ está na ilita, isso permitiu estimar o percentual de

Tabela 2 - Minerais identificados, suas respectivas composições centesimais e procedimentos para a quantificação dos minerais presentes nas amostras.

\begin{tabular}{|c|c|}
\hline MINERAIS & CÁLCULO COMPOSICIONAL \\
\hline Ilita (I) & $\begin{array}{l}\mathrm{I}=\mathrm{Mg0} \text { total } \times 100 / 3,11 ; \mathrm{K}_{2} \mathrm{O}(\mathrm{I})=7,26 \times \mathrm{I} / 100 \\
\mathrm{Al}_{2} \mathrm{O}_{3}(\mathrm{I})=17,02 \times \mathrm{I} / 100 ; \mathrm{SiO}_{2}(\mathrm{I})=54,01 \times \mathrm{I} / 100\end{array}$ \\
\hline Muscovita (Mu) & $\begin{array}{c}\mathrm{Mu}=\mathrm{K}_{2} \mathrm{O} \text { total }-\mathrm{K}_{2} \mathrm{O}(\mathrm{Mu}) \times 100 / 11,81 ; \\
\mathrm{Al}_{2} \mathrm{O}_{3}(\mathrm{Mu})=38,36 \times \mathrm{Mu} / 100 ; \mathrm{SiO}_{2}(\mathrm{Mu})=45,21 \\
\times \mathrm{Mu} / 100\end{array}$ \\
\hline Montmorilonita (Mt) & $\begin{array}{c}\mathrm{Mt}=\mathrm{Na}_{2} \mathrm{O} \text { total } \times 100 / 1,02 ; \\
\mathrm{Al}_{2} \mathrm{O}_{3}(\mathrm{Mt})=18,57 \times \mathrm{Mt} / 100 ; \mathrm{SiO}_{2}(\mathrm{Mt})=43,7 \times \\
\mathrm{Mt} / 100\end{array}$ \\
\hline Caulinita (C) & $\begin{array}{c}\mathrm{C}=\left[\mathrm{Al}_{2} \mathrm{O}_{3} \text { total }-\mathrm{Al}_{2} \mathrm{O}_{3}(\mathrm{I})-\mathrm{Al}_{2} \mathrm{O}_{3}(\mathrm{M})\right] \times 100 / 39,50 \\
\mathrm{C}=\mathrm{SiO}_{2} \text { total } \times 100 / 46,55\end{array}$ \\
\hline Quartzo (Q) & $\begin{array}{c}Q=\mathrm{SiO}_{2} \text { total }-\mathrm{SiO}_{2}(\mathrm{I})-\mathrm{SiO}_{2}(\mathrm{M})-\mathrm{SiO}_{2}(\mathrm{C})- \\
\mathrm{SiO}_{2}(\mathrm{Mt}) .\end{array}$ \\
\hline $\begin{array}{l}\text { Hematita + Goethita } \\
(\mathrm{H}+\mathrm{G})\end{array}$ & $\mathrm{H}+\mathrm{G}=\mathrm{Fe}_{2} \mathrm{O}_{3}$ \\
\hline Rutilo (R) & $\mathrm{R}=\mathrm{TiO}_{2}$ \\
\hline
\end{tabular}

CC - composição centesimal obtida a partir da fórmula química de cada mineral.
$\mathrm{K}_{2} \mathrm{O}$ proveniente da ilita, o restante foi atribuído à muscovita; 2) o $\mathrm{CaO}$ foi associado a montmorilonita; 3) Com base na proporção desses minerais foi quantificado o $\mathrm{SiO}_{2}$ e $\mathrm{Al}_{2} \mathrm{O}_{3}$ de cada um deles; 4) Subtraiu-se esses valores do $\mathrm{SiO}_{2}$ e $\mathrm{Al}_{2} \mathrm{O}_{3}$ obtido na análise química inicial (Tabela 2); 5) O novo valor de $\mathrm{Al}_{2} \mathrm{O}_{3}$ foi atribuído a caulinita e calculado quanto de $\mathrm{SiO}_{2}$ é necessário para sua formação; 6) $\mathrm{O}$ valor final de $\mathrm{SiO}_{2}$ foi considerado como quartzo; 5) o $\mathrm{TiO}_{2}$ foi atribuído ao rutilo e o $\mathrm{Fe}_{2} \mathrm{O}_{3}$ à hematita+goethita.

As análises químicas dos óxidos maiores $\left(\mathrm{SiO}_{2}, \mathrm{Al}_{2} \mathrm{O}_{3}\right.$, $\mathrm{Fe}_{2} \mathrm{O}_{3}, \mathrm{MgO}, \mathrm{CaO}, \mathrm{Na}_{2} \mathrm{O}, \mathrm{K}_{2} \mathrm{O}, \mathrm{TiO}_{2}$ e $\mathrm{P}_{2} \mathrm{O}_{5}$ ) foram feitas por ICP-AES, após fusão com $\mathrm{LiBO}_{2}$ e dissolução com água-régia. A perda ao fogo (P.F.) foi feita por gravimetria. Os elementos-traço (Mo, Cu, Pb, Zn, Ni, Mn, As, Cd, Sb, $\mathrm{Bi}, \mathrm{Ag}, \mathrm{Au}, \mathrm{Hg}$, Se, Ba, Be, Co, Cs, Ga, Hf, Nb, Rb, Sc, Sr, Ta, Th, U, V, W, Zr, Y, ETR) e isótopos de Pb por ICP-MS, após fusão com $\mathrm{LiBO}_{2}$ e dissolução com água-régia. Todas as análises químicas foram executadas pela Acme Analytical Laboratories LTD no Canadá.

$\mathrm{O}$ índice de intemperismo (CIA) foi calculado pela fórmula $\left.\mathrm{Al}_{2} \mathrm{O}_{3} /\left(\mathrm{Al}_{2} \mathrm{O}_{3}+\mathrm{CaO}+\mathrm{Na}_{2} \mathrm{O}+\mathrm{K}_{2} \mathrm{O}\right) \times 100\right]$ de Nesbitt e Young (1984) e Eu/Eu* por $[(\mathrm{Eu} / 0,087) \sqrt{(S m / 0,231) *(G d / 0,306)}$ )]. O delineamento estatístico foi realizado por análise de agrupamento do programa Statistica versão 9.0.

\section{RESULTADOS E DISCUSSÃO}

\section{Composição Granulométrica e Mineralógica}

Os sedimentos de fundo se caracterizam pela textura areia média, fina e silte-argila como as mais abundantes. Os sedimentos dos rios Sampaio, Marmelos, Antonio, Puruzinho 
e Jamari são essencialmente síltico-argilosos, enquanto os rios Madeira, Aripuanã, Manicoré e Machado são mais arenosos, especialmente os três últimos, onde predominam as fraçôes areia grossa e média (Tabela 1).

As fraçốes mais grossas são compostas essencialmente de quartzo (hialino, branco, fumé e rosado). Seus grãos têm granulometria uniforme e são arredondados, o que indica que passaram por longo transporte e suas áreas fontes estão distantes. Em lupa binocular foram identificados oólitos de óxido-hidróxido de ferro, feldspato, biotita, minerais opacos e fragmentos de rocha (arenitos e ígneas/metamórficas ácidas) e outros minerais transparentes (rutilo, zircão, turmalina entre outros), mas em concentração muito baixa. A fração fina contém, além de quartzo, caulinita, montmorillonita e illita+muscovita (Figura 2).

A quantificação da mineralogia, com base na difração de raios-x e na composição química, mostrou que o quartzo representa nos sedimentos do rio Madeira entre 70\% e 76\% (mais elevado para jusante), enquanto ilita, montmorilonita e caulinita são mais abundantes nos tributários, somando entre 37\% e 65\% (Figura 2). Nos sedimentos dos tributários, o quartzo é muito baixo no Puruzinho $(<1 \%)$ e alcança no máximo (49\%) no Marmelos. O Jamari diferencia-se dos demais por conter $25 \%$ de muscovita (Figura 2 ).

\section{Composição Química}

$\mathrm{O} \mathrm{SiO}_{2}, \mathrm{Al}_{2} \mathrm{O}_{3}$ e $\mathrm{Fe}_{2} \mathrm{O}_{3}$ apresentaram os percentuais mais elevados nos sedimentos de fundo do rio Madeira e de seus principais tributários. São seguidos de perda ao fogo (PF) e $\mathrm{K}_{2} \mathrm{O} . \mathrm{O} \mathrm{MgO}, \mathrm{TiO}_{2}, \mathrm{CaO}$ e $\mathrm{Na}_{2} \mathrm{O}$ têm valores menores e $\mathrm{P}_{2} \mathrm{O}_{5}$ e $\mathrm{MnO}$ são os mais baixos (Tabela 3).

Há forte correlação negativa entre $\mathrm{SiO}_{2} \mathrm{e}_{2} \mathrm{O}_{3}, \mathrm{Fe}_{2} \mathrm{O}_{3}$, $\mathrm{MgO}, \mathrm{K}_{2} \mathrm{O}, \mathrm{TiO}_{2}, \mathrm{P}_{2} \mathrm{O}_{5}$ e PF (Figura 3). O SiO $\mathrm{Sé}_{2}$ mais elevado $(>52,69 \%)$ especialmente nos sedimentos dos rios Madeira e Machado (varia entre $88,75 \%$ e $92,45 \%$ ) e, consequentemente é onde o $\mathrm{Al}_{2} \mathrm{O}_{3}$ é mais baixo $(<4,98 \%)$ (Tabela 3 e Figura 3). Os conteúdos de $\mathrm{Fe}_{2} \mathrm{O}_{3}$ sáo baixos nos do rio Madeira (< $3,03 \%$ ) e um pouco mais elevados nos dos tributários (até $7,01 \%$ no rio Jamari), e estáo relacionados à hematita e/ou goethita que forma oólitos na fração areia. Dentre os álcalis o $\mathrm{K}_{2} \mathrm{O}$ é o mais elevado, especialmente nos sedimentos dos rios Antônio, Sampaio, Manicoré e Puruzinho (entre 2,53\% e 3,50\%), e é seguido pelo $\mathrm{MgO}(\leq 1,42 \%)$ coincidentes com os maiores conteúdos de illita, muscovita e montmorilonita (Tabela 3 e Figura 2). $\mathrm{CaO}$ e $\mathrm{Na}_{2} \mathrm{O}$ são baixos, mas o segundo é um pouco mais elevado que o primeiro e náo diferenciam os sedimentos do rio Madeira em relação aos dos tributários (Tabela 3 e Figura 3). A PF é de no máximo 17,65\% nos sedimentos do rio Aripuaná e reflete a maior proporção de material síltico-argiloso nos deste rio e separa quimicamente os dos tributários, exceto o Machado, dos do rio Madeira.

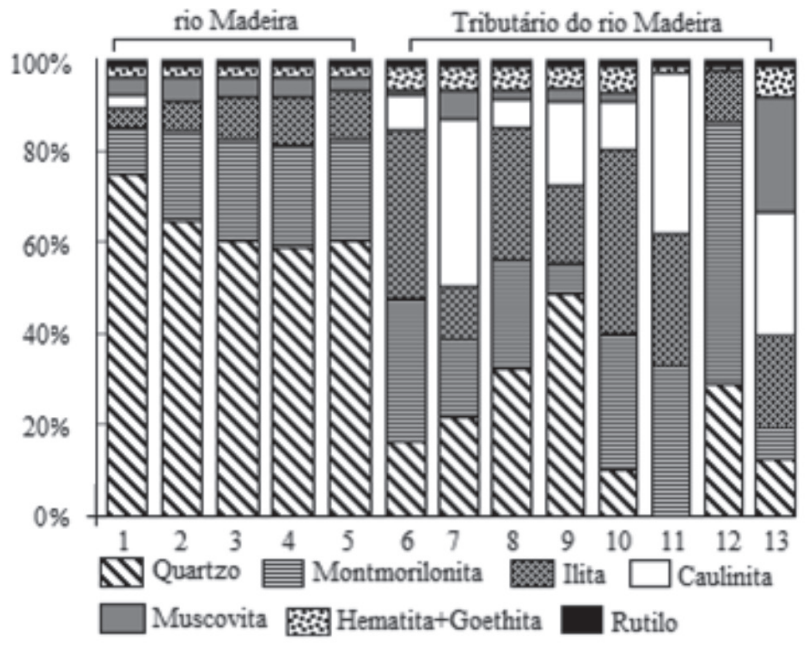

Figura 2 - Composição mineralógica dos sedimentos de fundo do rio Madeira e seus principais tributários ( 1 a 5 rio Madeira, 6 rio Sampaio, 7 rio Aripuanã, 8 rio Manicoré, 9 rio Marmelos, 10 rio Antônio, 11 rio Puruzinho, 12 rio Machado e 13 rio Jamari); Q - Quartzo, H+G - Hematita +Goethita, Mu - Muscovita, C - Caulinita, I - llita, Mt- montmorilonita.

$\mathrm{O} \mathrm{TiO}_{2}$ é baixo $(<1,30 \%)$ (Tabela 3$)$ e está relacionado ao rutilo detectado por DRX. Este elemento apesar dos baixos percentuais, assim como $\mathrm{P}_{2} \mathrm{O}_{5}(<0,28 \%)$ e $\mathrm{MnO}(<0,18 \%)$ mostra associação com os sedimentos dos tributários (Figura 3). O MnO, mais alto no rio Aripuanã $(0,18 \%)$, coincide com a presença de ocorrências manganesíferas nesse rio (Liberatore et al. 1972; Araújo et al. 1978; Silva 2009). Ao longo do Madeira há clara tendência de todos os principais óxidos $\left(\mathrm{Al}_{2} \mathrm{O}_{3}, \mathrm{Fe}_{2} \mathrm{O}_{3} \mathrm{MgO}, \mathrm{CaO}, \mathrm{Na}_{2} \mathrm{O}, \mathrm{K}_{2} \mathrm{O}, \mathrm{TiO}_{2}, \mathrm{P}_{2} \mathrm{O}_{5}\right.$ e $\mathrm{PF}$ ) diminuírem para jusante (Tabela 3).

O índice CIA (Nesbitt e Young 1984), calculado com base na relação entre $\mathrm{Al}_{2} \mathrm{O}_{3}$ e $\mathrm{CaO}, \mathrm{Na}_{2} \mathrm{O}$ e $\mathrm{K}_{2} \mathrm{O}$ igual a 50, indica que os minerais primários portadores desses elementos estão preservados e, portanto, o intemperismo é fraco na fonte dos sedimentos. Esta relação indica que as rochas fontes dos sedimentos do rio Madeira com CIA entre 71,46 e 73,62 estáo sob intemperismo um pouco menos intenso que as dos tributários com valores entre 78,70 e 92,49 (Tabela 3). $\mathrm{O}$ sedimento do rio Machado tem características próprias, possui CIA igual a 46,75 (Tabela 3). O grau de intemperismo do rio Madeira tem leve acréscimo de montante para jusante (Tabela 3).

\section{Elementos-traço}

Dentre os elementos-traços analisados, $\mathrm{Ba}$ e $\mathrm{Zr}$ têm os teores mais elevados nos sedimentos, ambos representam 63\% do conteúdo total desses elementos. O Ba alcança até $630 \mathrm{mg}$ $\mathrm{kg}^{-1}$, exceto no sedimento do rio Jamari e a montante do rio Madeira onde $\mathrm{Zr}$ alcança $1230 \mathrm{mg} \mathrm{kg}^{-1}$, enquanto o Ba está abaixo de $305 \mathrm{mg} \mathrm{kg}^{-1}$ (Tabela 3). Dentre os demais elementos 
Tabela 3 - Química dos sedimentos de fundo do rio Madeira e seus tributários, elementos maiores em \% e traços em mg $\mathrm{kg}^{-1}$ comparados com a crosta continental superior (CCS) e aos folhelhos australianos pós-arqueanos (PAAS) de Taylor e McLennan (1985).

\begin{tabular}{|c|c|c|c|c|c|c|c|c|c|c|c|c|c|c|c|c|c|}
\hline Ptos & 1 & 2 & 3 & 4 & 5 & Md & 6 & 7 & 8 & 9 & 10 & 11 & 12 & 13 & $\mathrm{Md}$ & $\mathrm{Md}$ & $\mathrm{Md}$ \\
\hline Local & MAD & MAD & MAD & MAD & MAD & MAD & SAM & ARI & MAN & MAR & ANT & PUR & MAC & JAM & TRIB & $\operatorname{CCS}$ & PAAS \\
\hline $\mathrm{SiO}_{2}$ & 91,30 & 88,75 & 87,38 & 86,71 & 87,40 & 88,31 & 61,39 & 52,69 & 69,15 & 71,29 & 58,37 & 68,17 & 92,45 & 57,22 & 66,34 & 65,91 & 62,83 \\
\hline $\mathrm{Al}_{2} \mathrm{O}_{3}$ & 3,60 & 4,98 & 5,54 & 5,91 & 5,32 & 5,07 & 17,67 & 20,93 & 13,66 & 12,51 & 19,57 & 13,93 & 1,15 & 18,30 & 14,72 & 15,24 & 18,92 \\
\hline $\mathrm{Fe}_{2} \mathrm{O}_{3}$ & 2,73 & 2,77 & 2,80 & 2,84 & 3,03 & 2,83 & 5,99 & 5,29 & 6,33 & 4,92 & 7,00 & 5,88 & 2,21 & 7,01 & 5,58 & 4,56 & 6,54 \\
\hline $\mathrm{MgO}$ & 0,15 & 0,26 & 0,32 & 0,37 & 0,38 & 0,30 & 1,31 & 0,35 & 1,01 & 0,53 & 1,42 & 1,15 & 0,54 & 0,41 & 0,84 & 2,24 & 2,26 \\
\hline $\mathrm{CaO}$ & 0,11 & 0,22 & 0,26 & 0,26 & 0,28 & 0,23 & 0,36 & 0,16 & 0,27 & 0,07 & 0,35 & 0,44 & 0,90 & 0,20 & 0,34 & 4,26 & 1,33 \\
\hline $\mathrm{Na}_{2} \mathrm{O}$ & 0,31 & 0,48 & 0,56 & 0,62 & 0,50 & 0,49 & 0,83 & 0,07 & 0,72 & 0,39 & 0,75 & 0,80 & 0,05 & 0,28 & 0,49 & 3,95 & 1,24 \\
\hline K20 & 0,87 & 1,18 & 1,35 & 1,48 & 1,23 & 1,22 & 3,20 & 1,47 & 2,55 & 1,61 & 3,50 & 2,53 & 0,36 & 1,78 & 2,13 & 3,33 & 3,76 \\
\hline $\mathrm{TiO}_{2}$ & 0,23 & 0,35 & 0,41 & 0,35 & 0,50 & 0,37 & 0,94 & 0,92 & 0,86 & 0,88 & 0,94 & 0,91 & 0,12 & 1,30 & 0,86 & 0,62 & 1,04 \\
\hline $\mathrm{MnO}$ & 0,05 & 0,05 & 0,06 & 0,06 & 0,06 & 0,06 & 0,15 & 0,18 & 0,15 & 0,11 & 0,16 & 0,14 & 0,08 & 0,16 & 0,14 & - & 0,12 \\
\hline $\mathrm{P}_{2} \mathrm{O}_{5}$ & 0,12 & 0,13 & 0,11 & 0,14 & 0,17 & 0,13 & 0,28 & 0,25 & 0,22 & 0,15 & 0,28 & 0,16 & 0,14 & 0,23 & 0,12 & - & 0,13 \\
\hline P.F & 0,63 & 0,95 & 1,21 & 1,34 & 1,26 & 1,07 & 7,94 & 17,65 & 5,16 & 7,57 & 7,75 & 5,83 & 0,98 & 12,94 & 8,22 & - & 6,01 \\
\hline CIA & 73,62 & 72,59 & 71,85 & 71,46 & 72,58 & 72,42 & 80,10 & 92,49 & 79,42 & 85,80 & 80,97 & 78,70 & 46,75 & 89,01 & 79,15 & - & - \\
\hline $\mathrm{Ba}$ & 175 & 275 & 296 & 323 & 264 & 267 & 588 & 435 & 427 & 297 & 630 & 479 & 584 & 402 & 480 & 550 & 650 \\
\hline $\mathrm{Zr}$ & 104 & 146 & 179 & 132 & 305 & 173 & 200 & 416 & 366 & 529 & 173 & 353 & 89,7 & 1230 & 420 & 190 & 210 \\
\hline $\mathrm{Rb}$ & 31 & 42 & 49 & 54 & 46 & 44 & 155 & 76 & 113 & 74 & 167 & 118 & 12 & 89 & 100 & 112 & 160 \\
\hline V & 22 & 29 & 37 & 39 & 40 & 33 & 125 & 83 & 95 & 82 & 143 & 103 & 17 & & 90 & 107 & 150 \\
\hline $\mathrm{Sr}$ & 32 & 48 & 60 & 63 & 59 & 53 & 103 & 37 & 80 & 56 & 106 & 93 & 38 & 53 & 71 & 350 & 200 \\
\hline $\mathrm{Zn}$ & 19,3 & 24,3 & 31 & 40 & 33 & 29,4 & 75 & 59 & 70 & 51 & 83 & 82 & 20,3 & 57 & 62,1 & 71 & 85 \\
\hline$Y$ & 8,8 & 12,7 & 13,8 & 13,8 & 15,4 & 12,9 & 34 & 40 & 34 & 29,4 & 32 & 36 & 5,4 & & 34 & 22,3 & 27,6 \\
\hline $\mathrm{Cu}$ & 12,3 & 7,9 & 16,3 & 22,4 & 12,2 & 14,2 & 20,3 & 8,1 & 22,3 & 29,1 & 23,6 & 37 & 23,8 & 9,5 & 21,7 & 25,3 & 50 \\
\hline $\mathrm{Nb}$ & 7,7 & 10,6 & 12,0 & 10,4 & 13,1 & 10,8 & 21,5 & 27,8 & 19,7 & 23,2 & 21,4 & 20,7 & 3,2 & 42,3 & 22,5 & 12,2 & 19,1 \\
\hline $\mathrm{Ga}$ & 5,1 & 6,5 & 7,3 & 8,4 & 6,9 & 6,8 & 22,6 & & & 16,4 & 24,8 & 18,5 & 2,3 & 2 & 19,5 & 17,0 & 20,0 \\
\hline $\mathrm{Pb}$ & 4,5 & 5,3 & 6,5 & 7,9 & 6,5 & 6,1 & 14,5 & 22,7 & 16,6 & 15,8 & 19 & 15 & 2,4 & 20,7 & 15,8 & 17,3 & 20,4 \\
\hline Co & 4,7 & 6,6 & 7,9 & 9,1 & 8,4 & 7,3 & 15,6 & 19,9 & 15,6 & 8,7 & 16,6 & 15,7 & 2,7 & 11,5 & 13,1 & 17,2 & 23,5 \\
\hline Th & 3,1 & 3,9 & 4.9 & 4,7 & 5,6 & 4,4 & 13,5 & 20,4 & 12,8 & 14,8 & 16,1 & 13 & 1,8 & 26 & 14,8 & 10,7 & 14,6 \\
\hline $\mathrm{Hf}$ & 2,4 & 3,9 & 4,5 & 3,5 & 7,3 & 4,3 & 5,4 & 11,1 & 9,2 & 13,0 & 4,5 & 9,5 & 2,4 & 33,2 & 11,2 & 5,8 & 5,4 \\
\hline Sc & 2,2 & 3,4 & 4,2 & 4,6 & 4,7 & 3,4 & 16,3 & 14,9 & 13,6 & 9,7 & 18,4 & 13,5 & 1,6 & 14 & 12,3 & 13,6 & 16,8 \\
\hline As & 4,2 & 5,3 & 4,8 & 6,0 & 4,2 & 4,9 & 10,1 & 0,9 & 8, & 4 & 11,1 & 9,4 & 0,5 & & 5,9 & 1,5 & - \\
\hline Cs & 1,1 & 1,5 & 1,8 & 2,1 & 1,9 & 1,7 & 10,5 & 5,1 & 7,7 & 5,8 & 12,9 & 7,7 & 0,3 & 4,5 & 6,8 & 4,6 & 15,0 \\
\hline $\mathrm{Au}$ & 2,5 & 4,1 & 1,8 & 1,7 & 1,5 & 2,3 & 3,5 & 4,5 & 2,4 & 3,2 & 1,9 & 2,4 & 2,0 & 3,5 & 2,8 & - & - \\
\hline U & 0,9 & 1,2 & 1,3 & 1,4 & 1,5 & 1,3 & 3,2 & 5,1 & & 3 & 3,5 & 3,5 & 3,8 & 6,8 & 4,1 & 2,8 & 3,1 \\
\hline W & 0,8 & 0,8 & 1,0 & 1,6 & 1,0 & 1,0 & 2,9 & 3,2 & 2,4 & 2,5 & 3,2 & 2,7 & 0,5 & 3,2 & 2,6 & - & 2,7 \\
\hline $\mathrm{Ta}$ & 0,6 & 0,7 & 0,8 & 0,7 & 0,8 & 0,7 & 1,4 & 2 & 1,3 & 1,8 & 1,5 & 1,5 & 0,2 & 2,8 & 1,6 & - & - \\
\hline $\mathrm{Al} / \mathrm{Pb}$ & 4234 & 4972 & 4510 & 3959 & 4331 & 4401 & 6649 & 4879 & 4355 & 4190 & 5451 & 4915 & 2536 & 4678 & 4682 & 4000 & - \\
\hline $\mathrm{Zr} / \mathrm{Co}_{0}$ & 22,0 & 22,2 & 22,6 & 14,5 & 36,3 & 23,9 & 36,3 & 12,8 & 20,9 & 23,5 & 66,1 & 10,8 & 22,5 & 33,2 & 28,3 & 11,1 & 9,1 \\
\hline $\mathrm{La} / \mathrm{Th}$ & 3,7 & 5,0 & 4,4 & 3,9 & 4,2 & 4,4 & 4,2 & 2,8 & 2,5 & 2,6 & 2,4 & 2,5 & 2,9 & 2,9 & 2,8 & 1,7 & 1,6 \\
\hline $\mathrm{Th} / \mathrm{Yb}$ & 3,4 & 3,3 & 3,5 & 3,5 & 3,6 & 3,5 & 3,6 & 3,9 & 4,3 & 3,6 & 4,3 & 4,9 & 3,4 & 3,2 & 3,9 & - & 0,6 \\
\hline $\mathrm{Th} / \mathrm{U}$ & 3,4 & 3,3 & 3,8 & 3,4 & 3,7 & 3,5 & 3,7 & 4,2 & 4,0 & 3,9 & 3,8 & 4,6 & 3,7 & 0,5 & 3,6 & 0,6 & 0,6 \\
\hline $\mathrm{Th} / \mathrm{Co}_{0}$ & 0,7 & 0,6 & 0,6 & 0,5 & 0,7 & 0,6 & 0,7 & 0,9 & 1,0 & 0,8 & 1,9 & 1,0 & 0,8 & 0,7 & 1,0 & 0,6 & 0,7 \\
\hline $\mathrm{Th} / \mathrm{Pb}$ & 0,7 & 0,7 & 0,8 & 0,6 & 0,9 & 0,7 & 0,9 & 0,9 & 0,9 & 0,8 & 0,9 & 0,8 & 0,9 & 0,8 & 0,9 & 2,8 & 2,6 \\
\hline $\mathrm{La} / \mathrm{Co}$ & 2,4 & 2,9 & 2,7 & 2,0 & 2,8 & 2,6 & 2,8 & 2,4 & 2,6 & 2,1 & 4,4 & 2,5 & 2,4 & 1,9 & 2,6 & 4,8 & 5,2 \\
\hline $\mathrm{Nd} / \mathrm{Pb}$ & 2,6 & 3,8 & 3,5 & 2,4 & 3,8 & 3,2 & 2,6 & 1,9 & 2,0 & 2,0 & 2,1 & 2,4 & 2,2 & 2,8 & 2,2 & 1,3 & 1,6 \\
\hline${ }^{206} \mathrm{~Pb} /{ }^{204} \mathrm{~Pb}$ & 19,7 & 19,8 & 16,0 & 18,5 & 18,7 & 18,5 & 19,6 & 20,0 & 18,4 & 19,0 & 18,4 & 19,1 & 19,0 & 21,6 & 19,4 & 19,2 & - \\
\hline${ }^{207} \mathrm{~Pb} /{ }^{204} \mathrm{~Pb}$ & 16,1 & 15,2 & 13,0 & 15,7 & 15,5 & 15,1 & 15,3 & 18,2 & 16,7 & 15,2 & 15,3 & 15,1 & 17,5 & 18,0 & 16,4 & 15,7 & - \\
\hline${ }^{208} \mathrm{~Pb} /{ }^{204} \mathrm{~Pb}$ & 43,6 & 40,2 & 38,5 & 38,7 & 39,2 & 40,1 & 40,5 & 46,7 & 41,2 & 37,2 & 37,1 & 41,7 & 43,3 & 42,3 & 41,3 & 39,5 & - \\
\hline
\end{tabular}



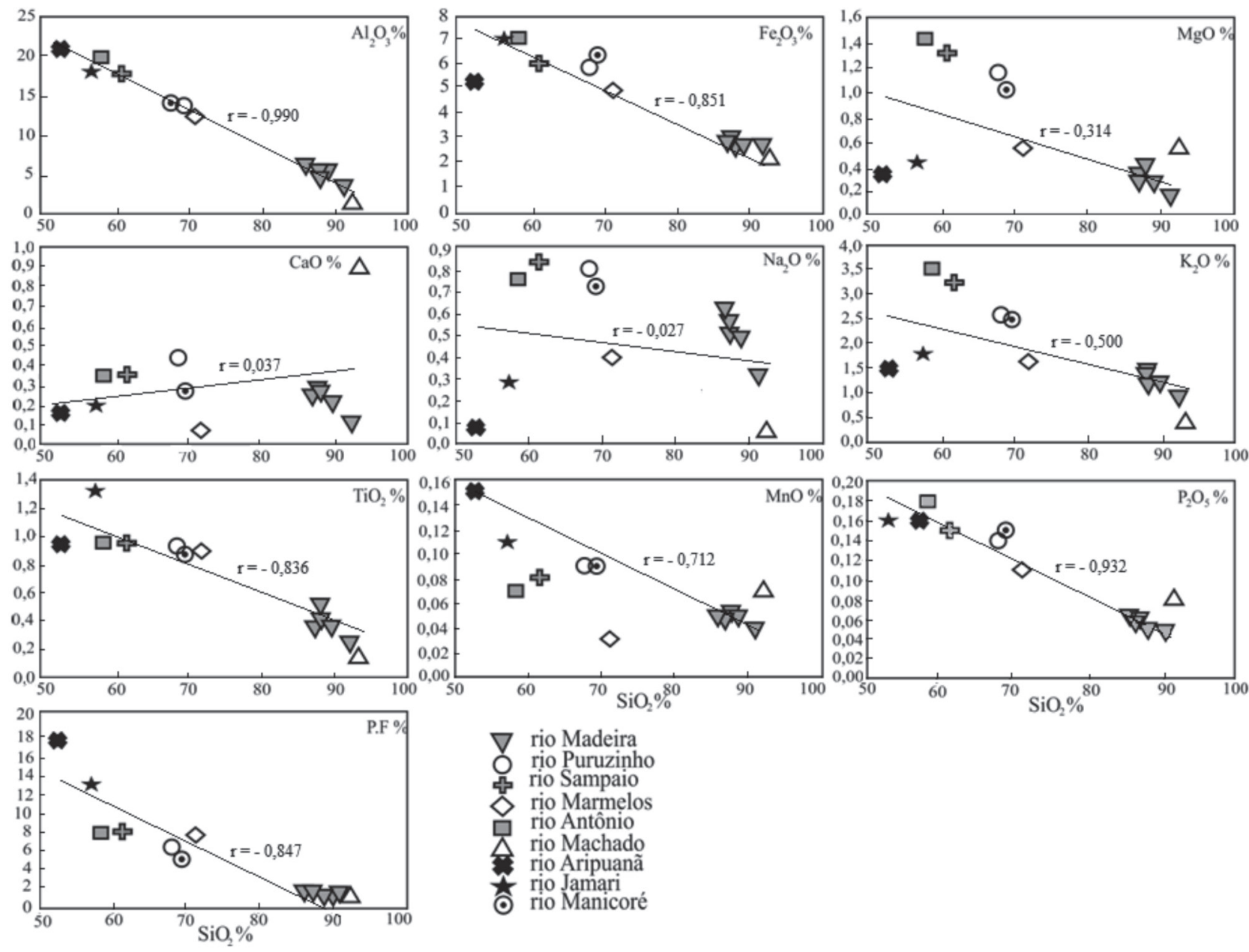

$\nabla$ rio Madeira

Ọio Puruzinho

rio Sampaio

rio Marmelos

rio Antônio

$\triangle$ rịo Machado

rio Aripuan

* rio Jamari

Figura 3 - Variações dos elementos versus $\mathrm{SiO}_{2}$ dos sedimentos de fundo do rio Madeira e de seus tributários

$\mathrm{Rb}, \mathrm{V}, \mathrm{Sr}, \mathrm{Zn}$ e Y variaram de 11,6 a $167 \mathrm{mg} \mathrm{kg}^{-1}$; $\mathrm{Cu}, \mathrm{Nb}$, $\mathrm{Ga}, \mathrm{Pb}, \mathrm{Co}$, Th, Hf, Sc, As, Cs, Au, U, W e Ta entre 0,2 mg $\mathrm{kg}^{-1}$ e 42,3 mg kg-1 $\mathrm{Be}, \mathrm{Ni}, \mathrm{Sn}, \mathrm{Ag}, \mathrm{Bi}, \mathrm{Cd}, \mathrm{Hg}, \mathrm{Mo}, \mathrm{Sb}, \mathrm{Se}$, Tl estão na maior parte abaixo do limite de detecção $(<0,01$ $\mathrm{mg} \mathrm{kg}^{-1}$ ). Todos esses elementos, assim como as razóes $\mathrm{Th} / \mathrm{U}$, $\mathrm{Th} / \mathrm{Co}, \mathrm{Th} / \mathrm{Pb}, \mathrm{Th} / \mathrm{Yb}, \mathrm{Al} / \mathrm{Pb}, \mathrm{Zr} / \mathrm{Co}$ estão mais concentrados nos sedimentos dos tributários, exceto no do Machado, do que nos do rio Madeira (Tabela 3). Ao longo do Madeira, quase todos os elementos têm conteúdos menores nos sedimentos para jusante.

Após normalizar os elementos-traço em relação à crosta continental superior (CCS) e aos folhelhos australianos pósarqueanos (PAAS), que também representam a composição média da crosta continental superior (Taylor e McLennan 1985), verifica-se que os sedimentos do rio Madeira são um pouco mais homogêneos e, em geral, empobrecidos em relação aos dos tributários, exceto em As, Au, W e Ta (Figura 4). Em relação à CCS, o Au mostra anomalia positiva (razão < 1) no Madeira o que reflete a mineralizaçáo nesse elemento nos sedimentos do rio; e Ni e em parte $\mathrm{Cu}$ e Co mostram anomalia negativa nos tributários. Há enriquecimento mais acentuado de $\mathrm{Zr}$, Hf, As, W e Ta, especialmente no sedimento do rio Jamari, e empobrecimento dos demais, com destaque para o Sr. O Sc está mais empobrecido no sedimento do Madeira que nos dos tributários. O do rio Jamari é o que apresenta, em geral, menor empobrecimento em elementos-traços e o do Machado a maior (Figura 4). Em relação aos PAAS, os sedimentos do rio Madeira também se diferenciam em relação aos tributários, têm padrão geral mais empobrecido, especialmente para jusante.

Dos ETR determinados, La, Ce e Nd apresentaram as concentraçôes mais elevadas (até $152 \mathrm{mg} \mathrm{kg}^{-1}$ ) (Tabela 4) e representam, aproximadamente, $79 \%$ do total destes elementos nos sedimentos, seguidos de Pr e Sm (até 15,7 mg $\mathrm{kg}^{-1}$ ); e Eu, Gd, Tb, Dy, Ho, Er, Tm, Yb e Lu têm os teores mais baixos (até $10,8 \mathrm{mg} \mathrm{kg}^{-1}$ ). Ao longo do rio Madeira, 

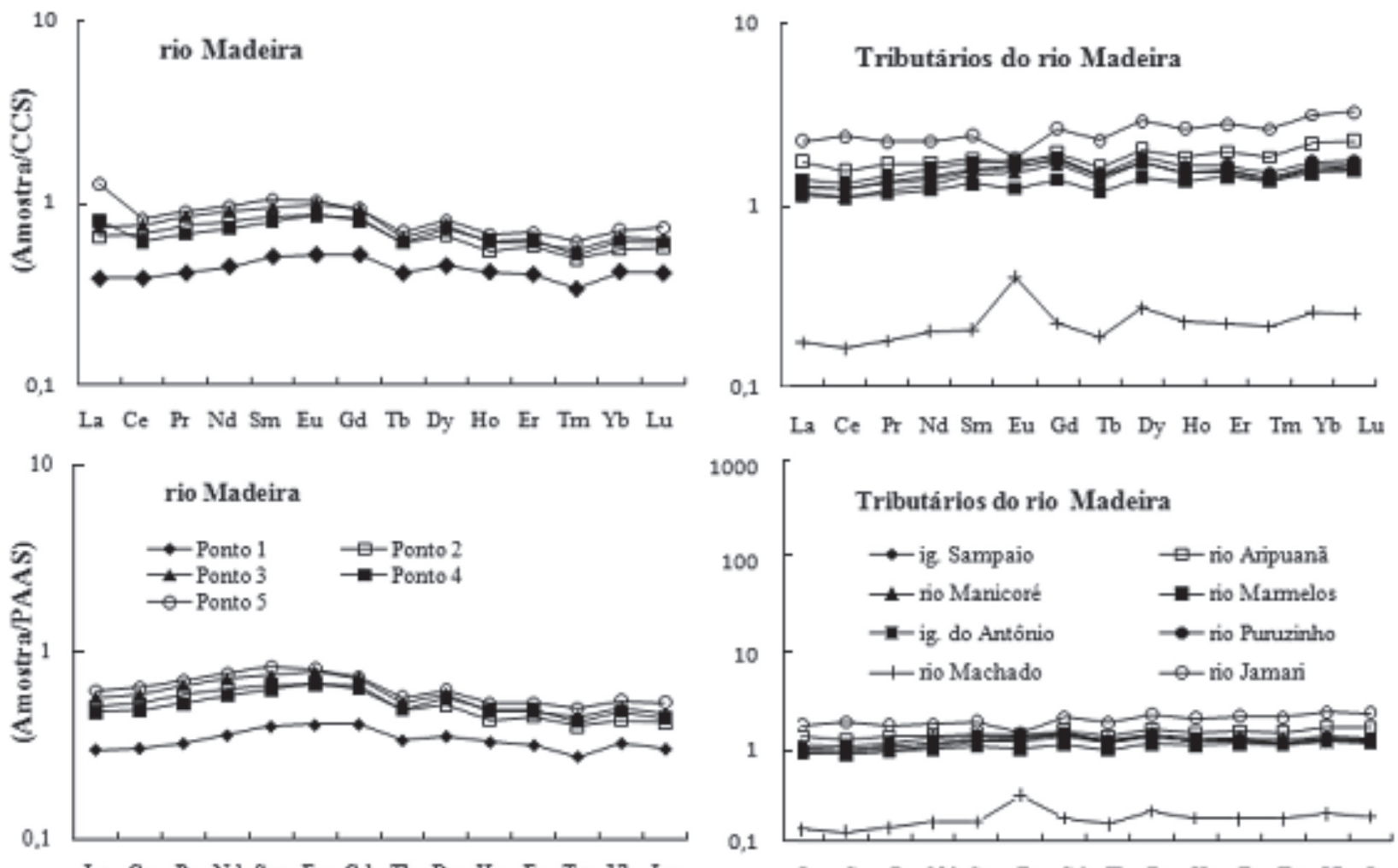

$\mathrm{La} \mathrm{Ce}$ Pr Nd $\mathrm{Sm}$ Eu Gd To Dy Ho Ex Tm Yb Lu
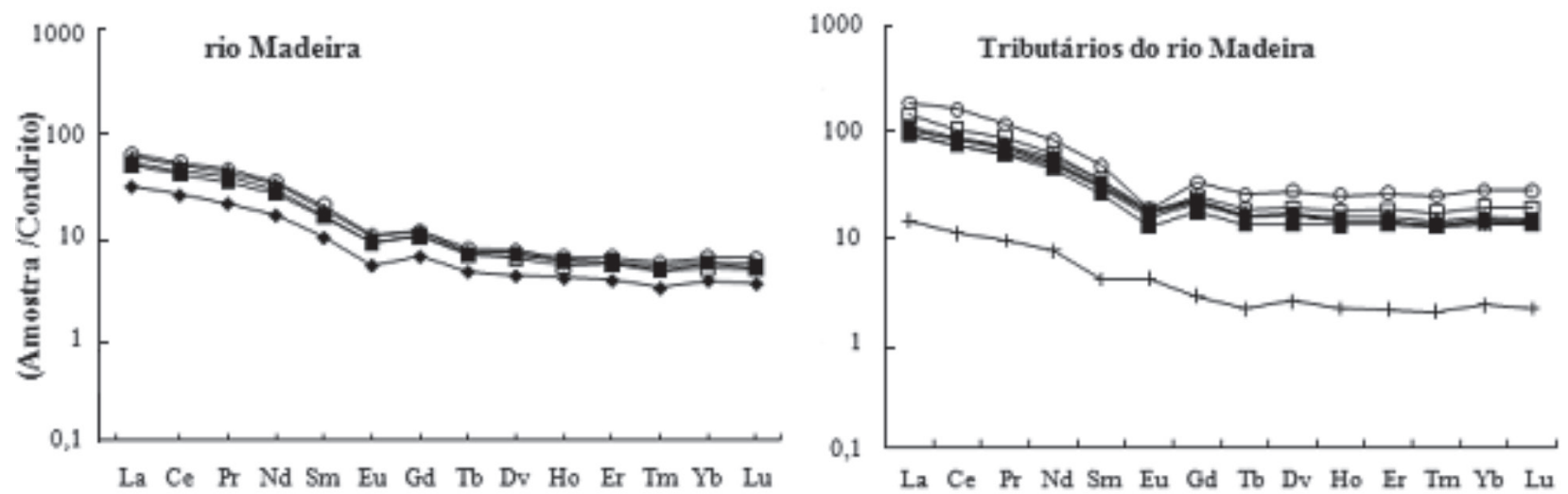

Figura 4 - Fracionamento dos elementos-traços em relação à CCS e ao PAAS de Taylor e McLennan (1985); aos condritos de Haskin et al. (1968) do rio Madeira e seus principais tributários. Au, As e Ta não foram normalizados pelos PAAS por não terem valor de referência.

todos decrescem nos sedimentos de montante $(\Sigma 122 \mathrm{mg}$ $\left.\mathrm{kg}^{-1}\right)$ para jusante $\left(\Sigma 59,1 \mathrm{mg} \mathrm{kg}^{-1}\right)$. Dentre os tributários, o sedimento do rio Jamari $\left(\Sigma 344 \mathrm{mg} \mathrm{kg}^{-1}\right)$ é o que contém o valor mais alto, enquanto o do Machado $\left(\Sigma 26,5 \mathrm{mg} \mathrm{kg}^{-1}\right)$ o mais baixo (Tabela 4).

Os ETR normalizados pela CCS e aos PAAS de Taylor e McLennan (1985) resultaram em curvas horizontalizadas, enriquecimento (razão <1) nos sedimentos dos tributários e empobrecimento nos do Madeira, exceto nos do rio Machado (Figura 4). O sedimento do rio Machado também se diferencia pela anomalia positiva de $\mathrm{Eu}\left(\mathrm{Eu} / \mathrm{Eu}^{*}=1,2\right.$ e 1,9 respectivamente - Tabela 4 ).

Em relação aos condritos (Haskin et al. 1968), os sedimentos estão enriquecidos, têm curvas com discreta concavidade para cima, pequena anomalia negativa em $\mathrm{Eu}\left(\mathrm{Eu} / \mathrm{Eu}^{*}=0,7\right.$ e 1,2 para os sedimentos do Madeira e tributários, respectivamente) e evidente enriquecimento de leves em relação aos pesados $\left((\mathrm{La} / \mathrm{Yb})_{\mathrm{N}}=\right.$ entre 7,9 e 9,5 para os sedimentos do rio Madeira e 6,2 e 7,5 para os tributários) (Figura 4). O empobrecimento e, consequentemente, o 
Tabela 4 - Elementos terras raras $\left(\mathrm{mg} \mathrm{kg}^{-1}\right)$ e razões de elementos dos sedimentos de fundo do rio Madeira e seus tributários, comparados com a CCS e PAAS de Taylor e McLennan (1985).

\begin{tabular}{|c|c|c|c|c|c|c|c|c|c|c|c|c|c|c|c|c|c|}
\hline Ptos & 1 & 2 & 3 & 4 & 5 & $\mathrm{Md}$ & 6 & 7 & 8 & 9 & 10 & 11 & 12 & 13 & Md & $\mathrm{Md}$ & $\mathrm{Md}$ \\
\hline Local & MAD & MAD & MAD & MAD & MAD & MAD & SAM & ARI & MAN & MAR & ANT & PUR & MAC & JAM & TRIB & CCS & PAAS \\
\hline $\mathrm{La}$ & 11,4 & 19,4 & 21,6 & 18,1 & 23,6 & 18,8 & 37,5 & 51,6 & 33,4 & 34,8 & 40,7 & 37,2 & 5,2 & 67,4 & 38,5 & 30 & 38,2 \\
\hline $\mathrm{Ce}$ & 24,4 & 42,6 & 47,2 & 38,7 & 51,5 & 40,9 & 77,8 & 98,3 & 70,1 & 69,5 & 83,3 & 77,9 & 10,3 & 152 & 79,8 & 64 & 79,6 \\
\hline $\mathrm{Pr}$ & 2,9 & 5,3 & 5,9 & 4,7 & 6,3 & 5,0 & 9,5 & 11,9 & 8,5 & 8,2 & 10,1 & 9,3 & 1,3 & 15,7 & 9,3 & 7,1 & 8,8 \\
\hline $\mathrm{Nd}$ & 11,5 & 20,4 & 22,9 & 18,6 & 24,4 & 19,6 & 37,0 & 43,6 & 33,4 & 31,4 & 40,8 & 35,9 & 5,2 & 58,0 & 35,7 & 26 & 33,9 \\
\hline $\mathrm{Sm}$ & 2,3 & 3,7 & 4,2 & 3,5 & 4,7 & 3,7 & 7,1 & 8,0 & 6,6 & 5,9 & 7,7 & 6,9 & 0,9 & 10,8 & 6,7 & 4,5 & 5,5 \\
\hline $\mathrm{Eu}$ & 0,5 & 0,8 & 0,9 & 0,7 & 0,9 & 0,7 & 1,4 & 1,5 & 1,3 & 1,1 & 1,5 & 1,4 & 0,4 & 1,6 & 1,3 & 0,8 & 1,0 \\
\hline $\mathrm{Gd}$ & 1,9 & 3,1 & 3,4 & 3,0 & 3,5 & 3,0 & 6,6 & 7,3 & 6,3 & 5,2 & 6,9 & 6,7 & 0,8 & 10,0 & 6,2 & 3,8 & 4,6 \\
\hline $\mathrm{Tb}$ & 0,3 & 0,4 & 0,4 & 0,4 & 0,4 & 0,4 & 0,9 & 1,0 & 0,9 & 0,8 & 0,9 & 0,9 & 0,1 & 1,5 & 0,9 & 0,6 & 0,7 \\
\hline Dy & 1,6 & 2,3 & 2,6 & 2,5 & 2,8 & 2,3 & 6,0 & 7,1 & 6,0 & 4,9 & 6,0 & 6,3 & 0,9 & 10,1 & 5,9 & 3,5 & 4,6 \\
\hline Ho & 0,3 & 0,4 & 0,5 & 0,5 & 0,5 & 0,5 & 1,2 & 1,5 & 1,2 & 1,1 & 1,2 & 1,3 & 0,2 & 2,1 & 1,2 & 0,8 & 0,9 \\
\hline $\mathrm{Er}$ & 0,9 & 1,3 & 1,4 & 1,4 & 1,6 & 1,3 & 3,6 & 4,5 & 3,5 & 3,3 & 3,5 & 3,8 & 0,5 & 6,4 & 3,6 & 2,3 & 2,8 \\
\hline Tm & 0,1 & 0,2 & 0,2 & 0,2 & 0,2 & 0,2 & 0,5 & 0,6 & 0,5 & 0,4 & 0,4 & 0,5 & 0,1 & 0,9 & 0,5 & 0,3 & 0,4 \\
\hline $\mathrm{Yb}$ & 0,9 & 1,2 & 1,4 & 1,3 & 1,5 & 1,3 & 3,4 & 4,7 & 3,6 & 3,4 & 3,3 & 3,8 & 0,6 & 6,8 & 3,7 & 2,2 & 2,8 \\
\hline Lu & 0,1 & 0,2 & 0,2 & 0,2 & 0,2 & 0,2 & 0,5 & 0,7 & 0,5 & 0,5 & 0,5 & 0,6 & 0,1 & 1,0 & 0,6 & 0,3 & 0,4 \\
\hline$\Sigma \mathrm{ETR}$ & 59,1 & 101 & 113 & 94 & 122 & 98 & 193 & 242 & 176 & 170 & 207 & 193 & 26,5 & 344 & 194 & 146 & 183 \\
\hline $\mathrm{Eu} / \mathrm{Eu}{ }^{*} \mathrm{a}$ & 0,003 & 0,007 & 0,006 & 0,007 & 0,006 & 0,006 & 0,006 & 0,003 & 0,003 & 0,004 & 0,004 & 0,003 & 0,003 & 0,026 & 0,007 & - & - \\
\hline $\mathrm{Eu} / \mathrm{Eu}{ }^{\star b}$ & 1,0 & 1,0 & 1,0 & 1,0 & 1,0 & 1,0 & 1,0 & 0,9 & 0,9 & 0,9 & 1,0 & 1,0 & 1,9 & 0,7 & 1,0 & - & - \\
\hline $\mathrm{Eu} / \mathrm{Eu}^{*} \mathrm{C}$ & 0,7 & 0,7 & 0,7 & 0,7 & 0,7 & 0,7 & 0,6 & 0,6 & 0,6 & 0,6 & 0,6 & 0,6 & 1,2 & 0,5 & 0,7 & & \\
\hline$(\mathrm{La} / \mathrm{Yb}) \mathrm{Na}$ & 7,9 & 9,3 & 9,2 & 8,2 & 9,5 & 8,9 & 7,0 & 7,3 & 6,3 & 7,2 & 7,5 & 6,6 & 6,2 & 7,5 & 7,2 & - & - \\
\hline$(\mathrm{La} / \mathrm{Yb}) \mathrm{N}$ b & 0,5 & 0,6 & 0,6 & 0,5 & 0,6 & 0,6 & 0,4 & 0,4 & 0,4 & 0,4 & 0,5 & 0,4 & 0,4 & 0,4 & 0,4 & - & - \\
\hline
\end{tabular}

Md: média; MAD: rio Madeira; SAM: rio Sampaio; ARI: rio Aripuanã; MAN: rio Manicoré; MAR: rio Marmelos; ANT: rio Antônio; PUR: rio Puruzinho; MAC: rio Machado; JAM: rio Jamari; TRl: Tributários; Eu/Eu*a: normalizados em relacão à crosta continental superior; Eu/Eu*b: normalizados em relacão ao PAAS (folhelhos australianos pós-arqueanos); Eu/ Euc: normalização pelos condritos de Haskin et al. (1968); (La/Yb)N a: normalizados em relação aos condritos; (La/Yb)N b: normalizados em relação aos PAAS; - valor não disponível na literatura.

fracionamento, são maiores no sedimento mais a jusante do rio Madeira.

\section{Isótopos de $\mathrm{Pb}$}

As razóes isotópicas de $\mathrm{Pb}$ nos sedimentos de fundo do rio Madeira e seus tributários variaram de 18,4 a 21,6 para ${ }^{206} \mathrm{~Pb} /{ }^{204} \mathrm{~Pb} ; 13,0$ a 18,2 para ${ }^{207} \mathrm{~Pb} /{ }^{204} \mathrm{~Pb}$ e 37,1 a 46,7 para ${ }^{208} \mathrm{~Pb} /{ }^{204} \mathrm{~Pb}$ (Tabela 4). Para testar se as razóes isotópicas de $\mathrm{Pb}$ são típicas de ambiente natural, foram utilizadas as razóes $\mathrm{Nd} / \mathrm{Pb}$ e Al/Pb (Millot et al. 2004). Este teste se faz necessário já que há facilidade do $\mathrm{Pb}$ ser adicionado ao meio ambiente, especialmente por meio de combustíveis, o que acarretaria razóes de $\mathrm{Pb}$ isotópico menores que as proveniente das rochas (Farmer et al. 1996; Bindler et al. 2001). Exceto os sedimentos do rio Machado cujas razóes $\mathrm{Nd} / \mathrm{Pb}$ e $\mathrm{Al} / \mathrm{Pb}$ estáo abaixo de 1,2 e 3000, respectivamente, há indicativo que o ambiente natural está preservado no restante da porção estudada da bacia do rio Madeira. Portanto, as razóes de $\mathrm{Pb}$ isotópico estão relacionadas às rochas fontes dos sedimentos. Apesar do indício de contaminação nos sedimentos do rio Machado, suas demais características granulométricas, mineralógicas e químicas sugerem um ambiente particular que pode estar relacionado à classificação hidráulica que levou à concentração de quartzo e não necessariamente contaminação.
Os sedimentos dos tributários têm maiores variaçôes isotópicas, enquanto os do Madeira são mais homogêneos com superposição dos campos dos sedimentos provenientes de cada um destes grupos (Figura 5). Os sedimentos dos rios Aripuaná, Machado e Jamari são os mais radiogênicos, enquanto os do Madeira (amostras 1, 2, 4 e 5) e os dos demais tributários são isotopicamente mais semelhantes, especialmente em ${ }^{207} \mathrm{~Pb} /{ }^{204} \mathrm{~Pb}$. Para jusante os sedimentos do rio Madeira têm tendência a serem menos radiogênicos para ${ }^{206} \mathrm{~Pb} /{ }^{204} \mathrm{~Pb}$ e ${ }^{208} \mathrm{~Pb} / 204 \mathrm{~Pb}$ apesar da amostra 3, a jusante da confluência com o Machado é a menos radiogênica de todas as amostras estudadas (Figura 5).

Os sedimentos à jusante do Madeira (amostras 1 e 2) e os dos rios Sampaio, Antônio e Machado tem semelhança isotópica com os sedimentos em suspensão do rio Amazonas de Allègre et al. (1996); os sedimentos dos terraços e planícies do Solimôes de Horbe e Trindade (2009) são compatíveis com a média da CCS de Taylor e McLennan (1985) e com a crosta continental da bacia Amazônia (Allègre et al. 1996), mas extrapolam o campo isotópico da maioria dos grandes rios do mundo (Millot et al. 2004). Entre os tributários, o sedimento do rio Sampaio é o que mais se assemelha com os dos rios Negro, Tapajós e Trombetas de Allègre et al. (1996) (Figura 5). 

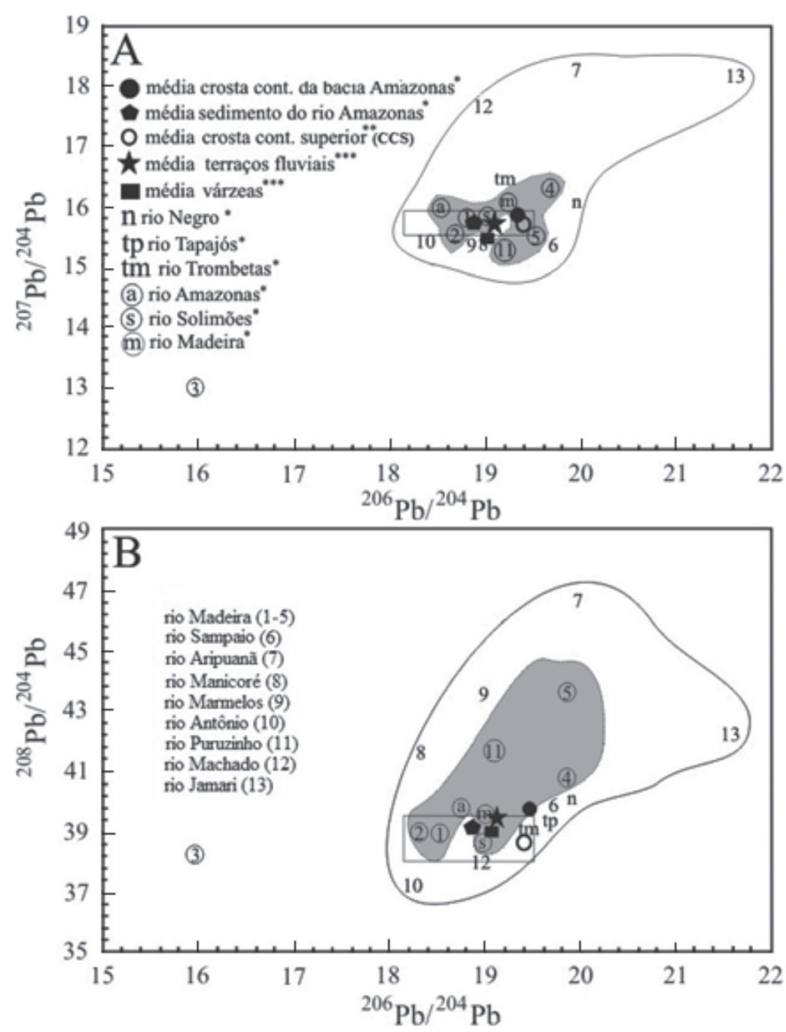

Figura 5 - Diagramas de correlações: ${ }^{206} \mathrm{~Pb} /{ }^{204} \mathrm{~Pb}$ versus ${ }^{207} \mathrm{~Pb} / 204 \mathrm{~Pb}$ e ${ }^{206} \mathrm{~Pb} /{ }^{204} \mathrm{~Pb}$ versus ${ }^{208} \mathrm{~Pb} /{ }^{204} \mathrm{~Pb}$ nos sedimentos de fundo do rio Madeira e seus principais tributários; *Allègre et al. (1996); **Taylor e McLennan (1985); $\star * \star$ Horbe e Trindade (2009), número e letras dentro do círculo representam os sedimentos de rios de água branca e os demais rios de água preta. 0 retângulo representa o campo de variação da composição isotópica do $\mathrm{Pb}$ de sedimentos de rio segundo Millot et al. (2004), média da crosta continental superior (CCS) de Taylor e McLennan (1985).

\section{Delineamento Estatístico}

A estatística multivariada por componentes principais (CP) indicou, com base no primeiro componente principal, que $\mathrm{SiO}_{2}, \mathrm{Al}_{2} \mathrm{O}_{3} \mathrm{Fe}_{2} \mathrm{O}_{3}, \mathrm{~K} \mathrm{~K}_{2} \mathrm{O}, \mathrm{TiO}_{2}, \mathrm{MnO}, \mathrm{P}_{2} \mathrm{O}_{5}, \mathrm{PF}, \mathrm{Zr}, \mathrm{Rb}$, V, Zn, Y, Nb, Ga, Pb, Co, Th, Hf, Sc Cs, U, W, Ta e ETR com cargas mais elevadas $(\geq 0,6)$ são os mais significativos para caracterizar os sedimentos estudados (Tabela 5). Com base nessas variáveis, foram obtidas as cargas dos dois primeiros componentes principais das amostras que sintetizam a diferenciação dos sedimentos da bacia do rio Madeira em dois grupos (Figura 6): os rios Madeira (1 a 5) e Machado (12) são quimicamente distintos dos demais afluentes.

Com base nos estudos realizados, há clara diferença na granulometria, mineralogia e química entre os sedimentos de fundo do rio Madeira, entre Porto Velho e sua foz no Amazonas, e seus tributários. Enquanto nos do rio Madeira há predomínio de areia média e fina, que se reflete na maior quantidade de quartzo, na maioria dos tributários (exceto Aripuanã, Manicoré e Machado) há mais silte + argila e, consequentemente, mais argilominerais, especialmente caulinita. Este fato é atribuído à classificação hidráulica exercida pelas suas águas que carreiam o fino em suspensão e o depositam na planície de inundaçáo do rio Madeira. Enquanto isso, o material mais pesado, transportado ao longo do leito, promove o arredondamento dos grãos de quartzo que se acumulam no fundo do rio.

O baixo fracionamento químico dos sedimentos demonstra a semelhança química destes com a crosta continental superior, enquanto as razóes $\mathrm{Th} / \mathrm{Co}, \mathrm{Th} / \mathrm{Pb}, \mathrm{Th} / \mathrm{Yb}, \mathrm{Al} / \mathrm{Pb}, \mathrm{Zr} / \mathrm{Co}$, geralmente mais baixas nos do rio Madeira, sáo indicativas de que há pelo menos duas fontes distintas nesse ambiente: uma fonte de rochas ígneas ácidas para os tributários, típicas do Cratón Brasileiro (Grupo Colider, Suite Intrusiva São Romão, Complexo Jamari); e uma mais máfica para o rio Madeira. Também é possível diferenciar ambientes geológicos distintos com base na razão $T h / U$, pois esta é mais elevada nas rochas mais antigas (Hemming e McLennan 2001). Nos sedimentos dos tributários essa razão varia entre 3,7 e 4,6 e, portanto, é indicativa de rochas fontes mais antigas e compatíveis com as do Cráton brasileiro, enquanto nos do rio Madeira, entre 3,3 e 3,8, estáo relacionadas às rochas cretáceas mais jovens dos Andes. Contudo, o sedimento do rio Jamari, com razão 0,5, assim como suas características químicas distintas (teores mais elevados de $\mathrm{TiO}_{2}, \mathrm{Zr}, \mathrm{Y}, \mathrm{Nb}, \mathrm{Ga}, \mathrm{Hf}, \mathrm{U}, \mathrm{Ta}$, ETR e menor de Cu e La/Co - Tabelas 3 e 4) e o do rio Machado, com os mais baixos teores de elementos- traços e ETR, diferenciam-se quimicamente dos demais tributários como exemplificado pela

Tabela 5 - Carga do primeiro componente principal da química dos sedimentos de fundo da bacia do Madeira.

\begin{tabular}{lccccc}
\hline Variáveis & $\mathrm{CP} 1$ & Variáveis & $\mathrm{CP} 1$ & Variáveis & $\mathrm{CP} 1$ \\
\hline $\mathrm{SiO}_{2}$ & 0,97 & $\mathrm{Zn}$ & $-0,86$ & $\mathrm{La}$ & $-0,96$ \\
$\mathrm{Al}_{2} \mathrm{O}_{3}$ & $-0,97$ & $\mathrm{Y}$ & $-0,97$ & $\mathrm{Ce}$ & $-0,94$ \\
$\mathrm{Fe}_{2} \mathrm{O}_{3}$ & $-0,96$ & $\mathrm{Cu}$ & $-0,10$ & $\mathrm{Pr}$ & $-0,96$ \\
$\mathrm{MgO}$ & $-0,55$ & $\mathrm{Nb}$ & $-0,93$ & $\mathrm{Nd}$ & $-0,97$ \\
$\mathrm{CaO}$ & 0,26 & $\mathrm{Ga}$ & $-0,99$ & $\mathrm{Sm}$ & $-0,97$ \\
$\mathrm{Na}_{2} \mathrm{O}$ & $-0,23$ & $\mathrm{~Pb}$ & $-0,96$ & $\mathrm{Eu}$ & $-0,98$ \\
$\mathrm{~K}_{2} \mathrm{O}$ & $-0,72$ & $\mathrm{Co}$ & $-0,84$ & $\mathrm{Gd}$ & $-0,99$ \\
$\mathrm{TiO}_{2}$ & $-0,99$ & $\mathrm{Th}$ & $-0,97$ & $\mathrm{~Tb}$ & $-0,98$ \\
$\mathrm{MnO} \mathrm{P}_{2} \mathrm{O}_{5}$ & $-0,93$ & $\mathrm{Hf}$ & $-0,69$ & $\mathrm{Dy}$ & $-0,98$ \\
$\mathrm{P.F}$ & $-0,82$ & $\mathrm{Sc}$ & $-0,95$ & $\mathrm{Ho}$ & $-0,98$ \\
$\mathrm{Ba}$ & $-0,86$ & $\mathrm{As}$ & $-0,36$ & $\mathrm{Er}$ & $-0,97$ \\
$\mathrm{Zr}$ & $-0,48$ & $\mathrm{Cs}$ & $-0,76$ & $\mathrm{Tm}$ & $-0,95$ \\
$\mathrm{Rb}$ & $-0,68$ & $\mathrm{Au}$ & $-0,44$ & $\mathrm{Yb}$ & $-0,95$ \\
$\mathrm{~V}$ & $-0,79$ & $\mathrm{U}$ & $-0,79$ & $\mathrm{Lu}$ & $-0,96$ \\
$\mathrm{Sr}$ & $-0,84$ & $\mathrm{~W}$ & $-0,97$ & $\mathrm{~V}$. total & $72 \%$ \\
\hline $\mathrm{V}$ & $-0,50$ & $\mathrm{Ta}$ & $-0,93$ & & \\
\hline
\end{tabular}

V. total - variância total 

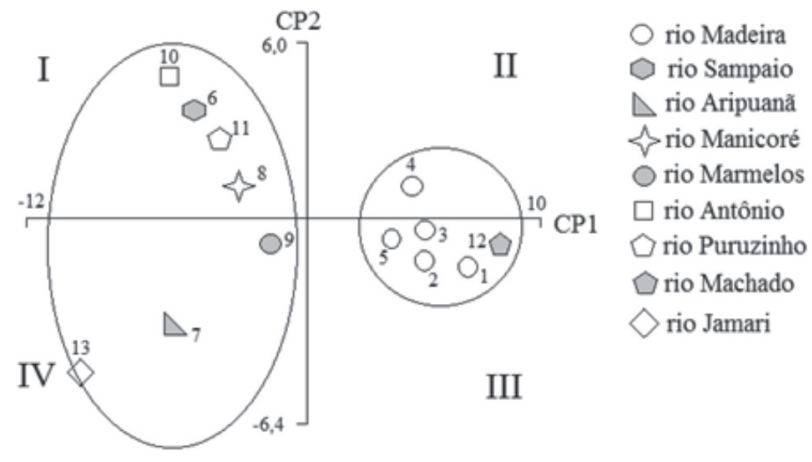

Figura 6 - CP1 versus CP2 das amostras de sedimentos de fundo da bacia do Madeira.

figura 6. Por outro lado, as razóes Th/Yb e La/Th (MacLennan et al, 1980) (Tabela 3) sugerem que o sedimento do Sampaio tende a uma fonte mais máfica semelhante à fonte dos sedimentos do Madeira. Essa fonte mais máfica pode estar relacionada ao fato de que o local onde foi coletada a amostra no rio Sampaio (6) ainda está na área de influência da várzea do Madeira, apesar de distar $65 \mathrm{~km}$ da confluência (Figura 1).

Essa diferenciação entre os sedimentos dos tributários se acentua quando considerada a razão isotópica do $\mathrm{Pb}$, inclusive há diferença em relação aos grandes rios do mundo e o Amazonas, Negro, Tapajós e Trombetas (Millot et al. 2004). Isto pode estar relacionado ao fato de que nos grandes rios, como o Madeira, os sedimentos são resultantes de mistura de material, o que aparentemente tende a homogeneizaçáo química, mas mantém a assinatura química da bacia. Os sedimentos dos tributários do Madeira, por representarem bacias menores, refletem as diferentes assinaturas isotópicas das rochas que percolam e que são as fontes dos seus sedimentos de fundo. Os de maior porte (Machado, Aripuanã e Jamari) e que cortam extensa porção do Cráton Brasileiro (Figura 1) têm os sedimentos mais radiogênicos $\left({ }^{207} \mathrm{~Pb} /{ }^{204} \mathrm{~Pb}\right)$ e, portanto, apresentam indicativo de rochas mais antigas, apesar da razão Th/U não corroborar com este fato no sedimento do rio Jamari. A homogeneidade química entre os sedimentos dos demais tributários (Sampaio, Manicoré, Marmelos, Antonio e Puruzino) deve-se, provavelmente, a maior parte das suas bacias estarem nas rochas cretáceo-cenozoicas das Formaçóes Alter do Chão e Içá e nos sedimentos quaternários, todos resultantes de etapas subsequentes de retrabalhamento das rochas mais antigas (Figura 1).

\section{CONCLUSÕES}

Com base no exposto, e apesar dos sedimentos de fundo estudados serem produtos do intenso intemperismo e erosão das rochas em condiçóes tropicais úmidas, foi possível reconstituir que: 1 ) rochas ígneas ácidas e máficas com idades distintas contribuíram como fonte de sedimentos da bacia do rio Madeira; 2) apesar dos tributários serem de porte bem menor que o rio Madeira, a contribuição dessas drenagens se faz notar no aumento da maturidade dos sedimentos para jusante; 3) há variação nos sedimentos de fundo do Madeira em função de aporte dos tributários; 4) o ambiente natural do rio Madeira ainda está preservado.

\section{AGRADECIMENTOS}

Os autores agradecem à Universidade Federal do Pará (UFPA) e ao Conselho Nacional de Pesquisa (CNPq), pela bolsa de doutorado da primeira autora e de pesquisadora da segunda.

\section{BIBLIOGRAFIA CITADA}

Allègre, C.J.; Dupré, B.; Négrel, P.; Gaillardet, J. 1996. Sr-Nd$\mathrm{Pb}$ isotopes systematics in Amazon and Congo river sistems: Constrain about erosion processes. Chemical Geology, 131: 93-112.

Araújo, H.J.T.; Rodarte, J.B.M.; Del'arco, J.O.; Santos, D.B. dos; Barros, A.M.; Tassinari, C.C.G.; Lima, M.I.C. de; Abreu, A.S.; Fernandes, C.A.C. .1978. Geologia. In: Brasil. DNPM. Projeto RADAMBRASIL. Folha SB.20-Purus. Rio de Janeiro, (Levantamento de Recursos Naturais), 561: 19-100.

Benedetti, M. F. 2003. The Amazon river: Behavior of metals Fe, Al, $\mathrm{Mn}$ ) and dissolved organic matter in the initial mixing at the Rio Negro/Solimoes confluence. Chemistry Geological, 197: 271-285.

Bindler, R; Renberg, I; Anderson, N. J; Appleby, P.G; Emteryd, O; Boyle, J. 2001. Pb isotope ratios of lake sediments in West Greenland: inferences on pollution sources. Atmospheric Environment, 35: 4675-4685.

Borges, J.B.; Huk, Y.; Moon, S.; Noh, H. 2008. Provenance and weathering control $\mathrm{n}$ river bed 308 sediments of the Eastern Tibetan Plateau ad the Russian Far East. Chemical Geology, 254: 52-72.

CPRM. 2001. Serviço Geológico do Brasil. Geologia e Recursos Minerais do Estado do Amazonas. Boletim Técnico.

CPRM. 2006. Mapa Geológico do Estado do Amazonas. Geologia e Recursos Minerais do Estado do Amazonas. Sistemas de Informação Geográfica - SIG, Programa Geologia do Brasil. Escala 1: 1.000.000, do Ministério de Minas e Energia. Rio de Janeiro. 1 CD-ROM. Programa Geologia do Brasil.

Dosseto, A.; Bourdon, B.; Gaillardet, J.; Allègre, C.J.; Filizola, N. 2006. Time scale and conditions of weathering under tropical climate: study of the Amazon basin with U-series. Geochimica and Cosmochimica Acta, 70: 71-89.

Dosseto, A.; Bourdon, B.; Gaillardet, L.; Bourgoin, M.; Allegre, C. J. 2006. Weathering and transport of sediments in the Bolivian Andes: Time constraints from uranium series isotopes. Earth and Panetary Science Letters, 248: 759-771. 
Elbaz-Poulichet, F.; Seyler, P.; Maurice-Bourgoin, L.; Guyot, J.L.; Dupré, C. 1999. Trace element geochemistry in the upper Amazon drainage basin (Bolivia). Mineralogical Magazine, 62: 418- 423.

Farmer, J. G; Eades, L. J; Mackenzie, A.B; Kirika, A; Bailey-Watts, T. E. 1996. Stable lead isotope record of lead pollution in Loch Lomond sediments since 1630 A.D. Environmental Science Technology, 30: 3080-3083.

Fralick, P.W; Kronberg, B.I. 1997. Geochemical discrimination of clastic sedimentary rock sources. Sedimentary Geology, 113: 111-124.

Gaillardet, J.; Dupré, B.; Allègre, C.; Négrel, P. 1997. Chemical and Physical Denudation in the Amazon River Basin. Chemical Geology, 142: 141-173.

Gibbs, R. J. 1967. Geochemistry of the Amazon river system, parte I. The factor that

control the salinity and composition and contration of the suspended solids. Geological Society of America Bulletin, 78: 1203 - 1232.

Goldstein, S.J.; Jacobsen, S.B. 1988. Nd and Sr isotopic systematics of river water suspended material: Implications for crustal evolution. Earth and Planetary Sciences Letters, 87: 249-265.

Guyot, J.L.; Jouanneau, J.M.; Soares, L.; Boaventura, G.R. ; Maillet, N.; Lagane, C. 2007. Clay mineral composition of river sediments in the Amazon Basin. Catena, 71: 340-356.

Haskin, L.A.; Haskin, M.A.; Frey, F.A.; Wildman, T.R. 1968. Relative and absolute terrestrial abundances of the rare earths, p. 889911. In: L.H. Ahrens Origin and distribution of the elements, Oxford. Pergamon, 1:

Hemming, S.R.; McLennan, S.M. 2001. Pb isotope compositions of modern deep sea turbidites. Earth and Planetary Science Letters, 184: 489-503.

Horbe, A.M.C; Trindade, I.R. 2009. Química, isotópicos de Pb e proveniência de sedimentos da bacia do rio Solimôes. Revista Brasileira de Geociências, 39: 635-646.

Liberatore, G.; Alecrim, J.D.; Medeiros, J.B.; Malouf, R.F.; Pinheiro, S.S.; Achão, S.M.; Santos, J.O.S. 1972. Project Aripuanã Sucunduri. Ministério de Minas e Energia - BRASIL. Contrato CPRM DNPM / Relatório inédito (in portuguese).

Lyons, W.B.; Bird, D.A. 1995. Geochemistry of the Madeira River, Brazil: comparison of seasonal weathering reactions using a mass balance approach. Journal of South American Earth Sciences, 8: 97-101.

Koppen, W. 1948. Climatology. A study of the Earth's climate. Mexico, 153-213 (in spanish, with abstract in english).
MacLennan S.M., Nance W.B., Taylor S.R. 1980. Rare earth element-thorium correlations in sedimentary rocks and the composition of the continental crust. Geochemistry and Cosmochemistry Acta, 44:1833-1839.

Martinelli, L.A.; Vitoria, R.L.; Damatte, J.L.I.; Richey, J.E.; Devol, A.H. 1993. Chemical and mineralogical composition of Amazon River floodplain sediments - Brazil. Applied Geochemistry, 8: 391-402.

Millot, R.; Allègre, C.J.; Gaillardet, J.; Roy, S. 2004. Lead isotopic systematics of major river sediments: a new estimate of the $\mathrm{Pb}$ isotopic composition of the Upper Continental Crustal. Chemical Geology, 203: 75-90

Mortatti, J.; Probst, J. L. 2003. Silicate rock weathering and atmospheric/soil CO 2 uptake in the Amazon Basin estimated from river water geochemistry: seasonal and spatial variations. Chemical Geology, Estados Unidos, 197: 177-196.

Nesbitt, H.W.; Young, G.M. 1984. Prediction of some weathering trends of plutonic and volcanic rocks based on thermodynamic and kinetic considerations. Geochemistry and Cosmochemistry Acta, 48: 1523-1534.

Seyler, P.; Boaventura, G.R. 2003. Distribution and partition of trace Metals in the Amazon Basin. Hydrological Processes, 17: 1345-1361.

Seyler,P.; Guyot, L.; Bougoin, M.; Sondag, F.; Elbaz-Poulichet, F.; Etcheber, H. 2003. Origin f trace elements in the Bolivian Amazonian drainage basin. Departament Geologie et Oceanographie, France.

Silva, P.M. 2009. Geologia, Mineralogia e Geoquímica de Crosta Manganifera, Alto Tapajós Basin, Apui - Amazonas. Dissertação (Mestrado em Geociências) - Universidade Federal do Amazonas. 80 pp.

Taylor, S. R.; McLennan, S.M. 1985. The Continental Crust: Its Composition and Evolution. Blackwell, Oxford, 312 pp.

Tardy, Y.; Bustillo, V.; Roquin, C.; Mortatti, J.; Victoria, R. 2005. The Amazon Biogeochemistry applied to river basin management. Part I. Hidroclimatology, hidrograph separation, mass transfer balances, stable isotopes, and modelling. Applied Geochemistry, 20: $1746-1829$.

Terezo, E. F; Góes Filho, L, Ferreira, A; Veloso, H. P; Fonseca, W. N; Silva, SB 1975. Folha Vegetação SB-21 - Tapajós. in: Brazil, DNPM. RADAMBRASIL. Cap IV - Vegetation. Rio de Janeiro.

Recebido em 04/07/2010

Aceito em 24/01/2011 